\title{
Discussion on the Information Collection Methods of Public Health Emergency Files
}

\author{
Wenni Wang*, Miaoying Lin, Wenpan Song, Fucai Huang, Baiyi Wang \\ Hainan General Hospital, Haikou, China \\ Email: *wangwenyi@163.com
}

How to cite this paper: Wang, W.N., Lin, M.Y., Song, W.P., Huang, F.C. and Wang, B.Y. (2021) Discussion on the Information Collection Methods of Public Health Emergency Files. Open Journal of Preventive Medicine, 11, 325-333.

https://doi.org/10.4236/ojpm.2021.117026

Received: June 30, 2021

Accepted: July 19, 2021

Published: July 22, 2021

Copyright $\odot 2021$ by author(s) and Scientific Research Publishing Inc. This work is licensed under the Creative Commons Attribution International License (CC BY 4.0).

http://creativecommons.org/licenses/by/4.0/

\begin{abstract}
In public health emergencies, the collection of archival information in the area of public health emergencies is very important, which can provide a reference for the early warning and processing mechanism. At the present stage, the unlimited demand of archival users for resources and the convenience of obtaining resources have become the two driving forces to promote the "transformation" and "growth" of archives. Public health emergencies, the transformation of archives collection and service mode, social media has become an indispensable platform for user information exchange, sharing and transmission, which requires archives to change the mode of archives acquisition and storage. Archival users require more interactive, targeted and cutting-edge forms of access and archival services are also developing toward diversified functions and connotations. Archival information resource sharing is also an important link in this development trend. This paper attempts to analyze the collection methods of archives departments in public health emergencies, and then puts forward the corresponding measures for archives departments to play their functions, such as flexibly solving the needs of archives access, strengthening the development of information resources, doing a good job in the collection of relevant archives, and publicizing archives work in combination with hot spots. This paper discusses the completeness of archival data collection, the means of archival management, the scientific classification of archival data, the ways of archival data collection and so on.
\end{abstract}

\section{Keywords}

Public Health Emergency, Files, Information, Management

\section{Introduction}

Archives departments shoulder the basic responsibilities and tasks of centralized 
and unified management of archives and related materials, maintenance of the true historical appearance, and service for the real social construction and the long-term needs of history, as well as the place for the public consultation of government information [1]. Therefore, when archives departments participate in the response to public health emergencies, their functional positioning should further combine their functional responsibilities and work tasks, highlight professional positioning and give play to professional advantages [2]. 1) Archives (rooms) at all levels and of all kinds can be said to be centralized and unified storage centers for the archives and materials of the unit or the profession in the region. Rich archive information and materials record the history of the locality or the unit, and also contain the infinite wisdom of predecessors, which can provide reference for handling current affairs. And archives department daily work content includes studying archives, archives information resource integration, information mining, etc. Therefore, it has accumulated rich experience and technology in the development of archival information resources, and has outstanding information integration and professional advantages. In response to public health emergencies, it can play the role of archives and provide relevant information reference for all levels and all kinds of units to play its function. We will play the role of assisting government. 2) Archival departments undertake the great responsibility of guarding and recording history and inheriting human civilization. The outbreak, response, prevention and control of public health events and related events are important history of the country. Archival departments have the responsibility to strengthen the collection and storage of relevant archives and protect the history of the country and human beings. 3) Archival departments keep rich archival materials and master important information resources. They are not only an important information center but also a rich treasure house of knowledge. Therefore, in the response to public health emergencies such as major epidemic prevention and control, archival departments can also play an active role in information dissemination and knowledge dissemination to record the victories achieved by the country in fighting against the epidemic, provide timely public information inquiry, give play to the publicity and education function of archives, guide people to correctly deal with the epidemic, and eliminate the fear of the public [3]. Therefore, in public health emergencies emergency work, archives in addition to the basic functions of normal control subjects positioning, more should play their own professional advantage, using its own resources, play a good information service, protect the function of history, and through the spread of information resources, assist relevant departments to do a good job of publicity, the spread of culture, establish and improve the management system of public health emergency files [4]. To improve the awareness of personnel involved in the disposal of public health emergency files, conscientiously do a good job in the filing of public health emergency files, and provide first-hand materials for the control of various emergencies in the future [5]. 


\section{Integrity of Archival Data Collection}

Solicitation of archives contain unconventional public health emergency department in charge of area, department of health, public security departments such as the government archives, and unconventional public health emergencies prevention and control of medical and health, urban change, people life is closely related to health prevention and control and save the value of documents, photos, video, physical objects, such as archives, It is extremely difficult to complete the collection of archival materials as shown in Figure 1 [6]. The management mechanism is not perfect all the time in the archives management of health emergencies. For instance archives are archived not timely, business archives are deposited in business section, did not archive to central archive room. It also fails to classify all business files as comprehensive in accordance with the detailed file classification of departments [7]. This leads to the archives cannot be fully utilized, reducing the timeliness of the use of archives. It takes a lot of time and effort to find the files before each use. It greatly reduces the role of archives management. When using information technology to manage electronic files, because the information technology is not mature enough, many electronic files are prone to damage and cannot be used [8].

\section{Diversified Archival Data Collection Modes}

Due to the unique value of health emergency archives and the particularity of file work, as well as the strong transmissibility of COVID-19, traditional collection methods cannot meet the requirements of complex public health emergency archives collection [9]. How to use digital technology, non-contact and other methods, through active collection, tracking collection, cooperative collection and acceptance

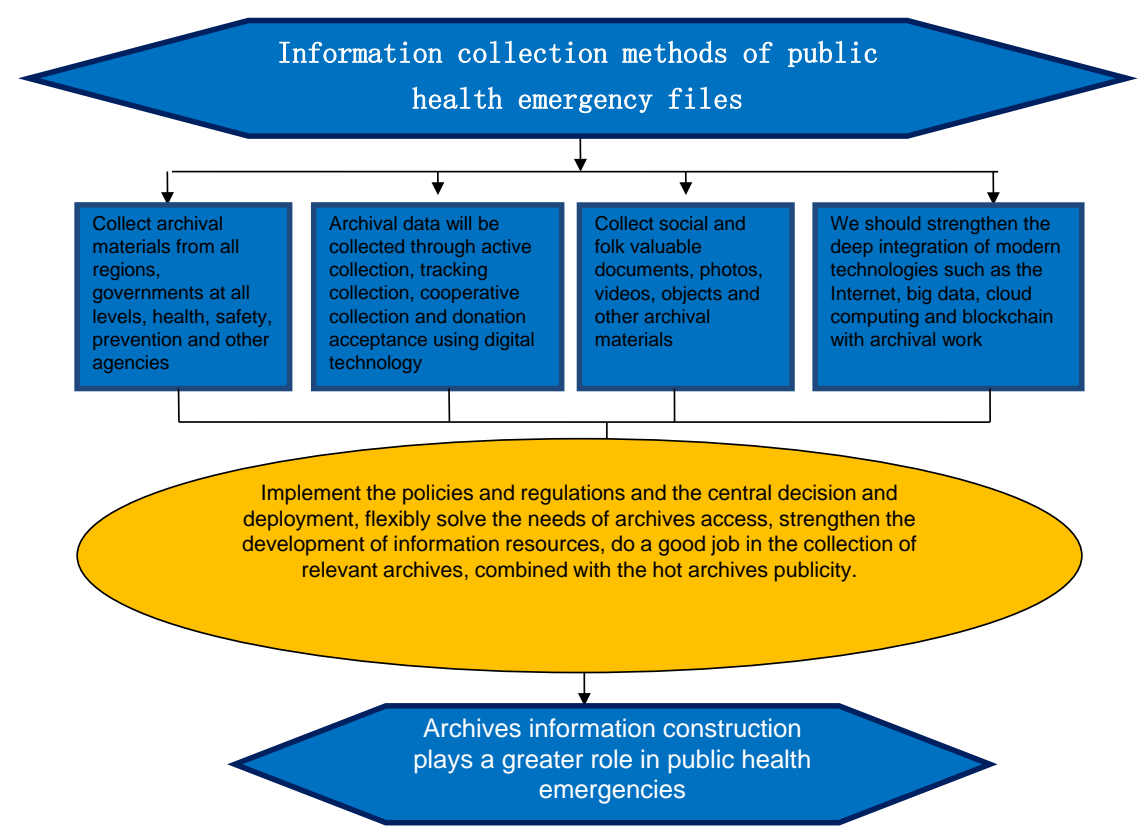

Figure 1. Public health emergency file information collection pattern map. 
of donations and other ways to collect archive data, is the key to solve the subject; During the special period, in addition to innovating forms and solving information service needs by means of remote file retrieval, archives departments should devote themselves to archive services with a proactive attitude, explore potential archive information service needs in the epidemic environment, and proactively provide information retrieval services that meet the needs of the epidemic [10]. For example, the national comprehensive archives at all levels can speed up the collection of current government information documents according to the needs of epidemic prevention work, so as to make them available for use: Organize archival compilation and research personnel to dig deeply the archival resources, collect and edit the archival materials of the Party and government's response to epidemics, natural disasters and other emergencies into archival reference materials, and timely report them to leaders at all levels for reference, so as to provide reference for the government's decision-making: Archives (rooms) of medical institutions should strengthen the analysis of previous case files, thus forming a summary of their work experience in dealing with infectious diseases, and providing reference for the institution to receive patients and strengthen daily management [11]. Construction of subject database should be conducted, barriers between regions, institutions and industries should be broken, and integration and mining of archival information resources of all regions and units should be strengthened, as well as regional cooperation and cooperation in response to public health emergencies should be strengthened, so that archival information can play a greater role.

\section{Scientific Classification of Archival Data}

The collected materials include paper documents, electronic documents and physical objects, etc. How to classify them scientifically and how to own the copyright are the problems that need to be solved. As China enters a new stage of building a modern socialist country in all respects, The development of social economy and the progress of science, public health emergencies happen, in the prevention and control of epidemic at the same time, explore and gradually to the informatization management of the emergencies, sharing and coordination model, battle runoff epidemic prevention and control of the present and future response to major public health emergencies, has irreplaceable important significance [12]. Public health emergencies prevention and control the collection of archives, should not only include the central, provincial and municipal governments at all levels to do a good job in epidemic prevention and control work issued executive orders, documents and all departments units to implement the policies and regulations and the central deployment and issued relevant documents, the cases of medical institutions archives and other common documents, professional files, and pay special attention to the special carrier of archives collection, Work such as the doctor's diagnosis and treatment records, notes, reflecting a public health emergency outbreak typical character, typical deeds, record the condition of or- 
dinary people living in the special period of photography, sound recording, video, video, media, sing war "epidemic" of the spirit of calligraphy, painting, sculpture, poetry, prose literature manuscripts and other art classes, such as physical files, etc. [13], These are vivid historical records and precious documents of epidemic prevention and control.

\section{Means of Archives Management}

Archives department should take the initiative to comply with the trend of social informatization, strengthen the consciousness of new media, use "Internet+" way of thinking and innovation, to speed up the epidemic prevention and control use of the integration of archives, carry forward the "epidemic" positive energy, strengthen the Internet, big data and cloud computing, block chain of modern science and technology with the depth of the archives work, speed up the construction of archives, and wisdom to build digital management platform, Improve the epidemic prevention and control archive database, promote the construction and sharing of archive data resources, and build a linkage mechanism [14]. It has always adhered to the leadership of the Party, adhered to the concept of putting life first and people first throughout, provided the government with reference services for administration management, publicity and education, and special technologies, jointly responded to public health emergencies, provided reference basis for early warning and treatment mechanism, and played the due role of archives work in boosting economic development [15]. At present, the public health emergency archives management should be taken to convert digital paper files information, using computer technology and modern management technology combine to store all kinds of information, the paper files, the traditional media such as audio and video files and have been filing of electronic archives, using existing software by archives management department store, catalog, and retrieval, unified management and use, Improve management efficiency [16].

Increase the information construction of public health emergency archives: with the development of electronic archives information, the traditional file management mode is gradually changing to the digital management mode, so it is very necessary to be familiar with information technology and professional technology of archives, and form a network management platform for public health event archives. In the process of public health emergency archives management, it is necessary to accelerate the transformation of traditional paper files into electronic data mode, and replace paper files with electronic information mode. At the same time, on the basis of the existing platform software, we should vigorously explore the establishment of the national archives database or realize the online information retrieval and digital information sharing of the national public health emergency network based on the basic data of the National Public Health Center, so as to improve the classification of archives catalog and information inquiry to the maximum extent and improve the utilization rate of archives. 


\section{Give Play to the Functions of the Archives Management Department. Speed up Troop Building}

In the early stage of public health emergencies [17], management departments should do a good job in the collection and sorting of different carrier materials, such as words, audio and video, which are formed directly in the process of handling public health emergencies and have preservation value, and guide them to file well and carry out centralized management, so as to ensure the integrity of the archives and provide effective services for future utilization [18]. Strengthening the file management of public health emergencies [19], archives management departments should not only before the occurrence of major public health emergencies, but also in the process and after the occurrence of events should go to the first line of the event, the real record, reflect the actual situation, do a good job in the collection, collation and preservation of archival materials. We should effectively monitor and control major public health emergencies. Supervise the archives scattered in different business departments to collect and organize in time. Ensure archival materials are complete, complete and secure [20]. In order to make the archives of public health emergencies develop to the modernization and information construction, it is urgently needed to cultivate compound archives management talents [21]. At present, the quality of the personnel in the archives management department is uneven, and the business level and ability are restricted. Have direct influence to do file management work well. Therefore, while constantly improving the quality and ability of archivists, we must strengthen the training of staff archives management business. The training of computer application knowledge, network knowledge and information related technical knowledge should be strengthened, and the ability of archives management workers to master and use computer network system to carry out work should be improved [22], so as to provide strong technical support for information resource sharing of public health emergencies.

\section{Conclusion}

In short, the information construction of public health emergency files should start from the actual situation, according to the specific situation of each unit to configure practical hardware equipment, which can meet the needs of the work. Height cannot be sought. Information technology is the fastest developing technology in today's society. Therefore, in the construction of archive information, we should boldly explore and adopt new technology [23]. At the same time, attention should be paid to the maturity of technology [24]. In short, in the information management and construction of public health emergency files, we should continue to explore and summarize experience. Problems are found and effective measures are taken to solve them [25]. The information construction of public health emergencies should pay attention to the construction of archival database, the construction of archival information standardization and the construction of archival information security system to meet the needs of public health emer- 
gencies for archival information. An important symbol of archival informatization is information sharing. Standardization of archival information is the basis of information sharing, and there is no informatization without standardization [26]. Establishing and perfecting the security system of archives information is the key link of the construction of archives information. Therefore, we should do a good job of information security while grasping the construction of information. Information construction of emergency public health event files is a systematic project. It is necessary to make reasonable arrangements and overall planning [27]. Information construction of public health emergency archives is a research topic of archives management department in recent years. To public health emergencies file system, comprehensive and intact, and then to the informatization construction, we must first do a good job in planning the archives informatization construction work on the leaders at all levels work agenda, the implementation of the responsibility, every year for archives informatization construction by people, money and investment, construction and perfect, to accumulate and summarize experience. The digitization and informatization construction of public health emergency archives management can be popularized and promoted as soon as possible, and the informatization construction of archives can play a greater role in public health emergency [28] [29]. In the face of public health emergencies, archives departments should consciously shoulder the responsibility, take the initiative to act, actively participate, take effective measures, give play to the functions of archives departments, make overall plans for archives work, and make their due contributions to the emergency work of public health emergencies.

\section{Funding}

Social Science Project of Hainan Province in 2021: No. HNSK(ZC)21-105.

\section{Conflicts of Interest}

The authors declare no conflicts of interest regarding the publication of this paper.

\section{References}

[1] Ji, Z.N. (2004) A Study on the Development of the Disease Prevention and Control Department Archives. Practical Preventive Medicine, 1L, Article No. 1078.

[2] Cui, Y., Chen, M. and Xu, X. (2012) Introduction of Special Working Mechanism to Manage Public Health Emergencies. China Medical Innovation, 9, 148-149.

[3] Jing, Z. and Li, S. (2010) Some Understandings on the Management of Public Health Emergency Files. Historical Records of Heilongjiang Province, No. 7, 57-56.

[4] Li, W., Li, Y. and Jiang, Q. (2010) Research on the Information Construction of Public Health Emergency Command System. Medical Equipment, 99, 100-102.

[5] Peng, J., Kuang, Y. and Wu, Z. (2011) Probe into Archives Management of Public Health Emergencies. Archives Time and Space, No. 6, 34-35.

[6] Gao, L. and Shen, Y. (2003) The Characteristics and Requirements of Emergency 
Archival Work-From the SARS Archival Work. Archives of China, No. 10, 40-41.

[7] Wang, J. (2016) Problems and Countermeasures in Cadre Personnel Archives Management. Human Resource Management, No. 8, 242-243.

[8] Zhang, Z.-B. (2014) How to Strengthen the Management of Cadre Personnel Archives. Cooperative Economy and Science, No. 20, 121.

[9] Shang, G. (2007) A Brief Discussion on Maritime Emergency Command. China Maritime Science, No. 10, 56-59.

[10] Sheng, J. and Liu, Z. (2005) Key Technology and Overall Design of Earthquake Emergency Command System. Seismological and Geomagnetic Observation and Research, 26, 108-109.

[11] Gai, C., Weng, W. and Yuan, H. (2009) Review of Public Safety in Viewpoint of Complex Networks. AIP Conference Proceedings, 1233, 801-805. https://doi.org/10.1063/1.3452281

[12] Fan, W.C. (2007) Advisement and Suggestion to Scientific Problems of Emergency Management for Public Incident. Bulletin of National Science Foundation of China, No. 2, 71-76.

[13] Liu, T. (2005) A New Approach to Emergency Information Systems for Public Events. Information Technology Construction, No. 9, 15-17.

[14] Zheng, H. (2010) Challenges and Countermeasures of Emergency Management. Leadership Science, No. 10, 55-56.

[15] Xue, L. and Zhu, Q. (2003) A Study on the Management of Public Health Emergencies in the United States. Chinese Administration, No. 8, 51-56.

[16] Zhang, M. (2003) A Review of the Crisis Management System in the United States and Its Role in Preventing SARS. Chinese Administration, No. 7, 55-59.

[17] Friedman, F.D. (1995) Public Relations in Disaster Management and Planning Emergency Physicians. Journal of Emergency Medicine, 13, 661-668.

[18] Zheng, J. (2007) A Study on the Construction of Public Health Emergency Response System. Chinese Journal of Public Health Management, 23, 503-504. https://doi.org/10.1016/0736-4679(95)00075-L

[19] Huang, W., Lv, S., et al. (2003) A Study on the Construction of Public Health Emergency System in China. Chinese Journal of Hospital Management, 19, 577-579.

[20] Wang, J. and Wang, X. (2012) A Review of Public Health Emergency Management in China. China Market, No. 26, 33-34.

[21] Chunyu, M., Cheng, Y. and Luo, L. (2007) A Study on the Organizational Innovation of Public Health Emergencies in Japan. Modern Preventive Medicine, No. 13, 2405-2409.

[22] Scanlon, J. (1994) 111e Role of EOCs in Emergency Management: A Comparison of American and Canadian Experience. International Journal of Mass Emergencies and Disasters, 12, 51-75.

[23] Papagiotas, S., Frank, M., Bruce, S. and Posid, J.M. (2012) From SARS to 2009 H1N 1 Influenza: The Evolution of a Public Health Incident Management System at CDC. Public Health Repots, 127, 267-274. https://doi.org/10.1177\%2F003335491212700306

[24] Shen, S.Y. and Shaw, M.J. (2004) Managing Coordination in Emergency Response Systems with Information Technologies. Proceedings of the 10 th Americas Conference on Information Systems, New York, 2004, 2110-2120.

[25] Annelli, J.E. (2006) The National Incident Management System: A Multi-Agency 
Approach to Emergency Response in the United States of America. Revue Scientifique Et Technique, 25, 223-231.

[26] Robert Koch Institute (2011) EHEC/HUS 0104: H4 Outbreak, Germany, May/June 2011: Technical Report. Bedim Robert Koch Institute, 3-5.

[27] Cui, Y., Tan, J. and Song, Y. (2011) Cluster of Escherichia coli Haemorrhagic Bacteria: A Cause of the Outbreak in Germany in 2011. Chinese Journal of Preventive Medicine, $45,581-582$.

[28] Zhao, F., Fu, C., Jiao, Y., et al. (2012) Study on the Construction of Public Health Emergency Command System at Home and Abroad. Chinese Journal of Health Information Management, No. 9, 25-29.

[29] Shen, S.Y. and Shaw, M.J. (2004) Using Information Technology to Manage and Coordinate Public Health Emergency Response Systems. Proceedings of the 10 th American Information Systems Forum, New York, 2004, 2110-2120. 